\title{
CHALLENGES FACED BY VASCULAR SURGEONS IN ACCEPTANCE OF THEIR SPECIALTY BY MEDICAL COMMUNITY OF PAKISTAN
}

\author{
Muhammad Jamil, Brekhna Jamil*, Aaiza Aman**, Rashid Usman*** \\ Combined Military Hospital/National University of Medical Sciences (NUMS) Rawalpindi Pakistan, *Khyber Medical University, Peshawar Pakistan, \\ **Fouji Foundation Hospital, Rawalpindi Pakistan, ${ }^{* * *}$ Combined Military Hospital Lahore/National University of Medical Sciences (NUMS) Pakistan
}

\section{ABSTRACT}

Objective: To determine the challenges being faced by vascular surgeons in acceptability of their specialty by the medical community of Pakistan.

Study Design: Qualitative case study.

Place and Duration of Study: Various training institutes \& teaching hospitals all over the Pakistan, from Sep 2019 to Feb 2020. Methodology: Semi structured interview format comprising of a series of open ended and broad questions to get maximum relevant information, were sent to 13 surgeons (vascular and part time vascular surgeons) practicing vascular surgery at least for the last five years in various training institutes and teaching hospitals of Pakistan. Interviews were audio recorded on telephone and in persons. The data was transcribed, cleansing was done, and analyzed through inductive and thematic content analysis.

Results: Handful of qualified vascular surgeons, inadequate vascular training program, part time vascular surgery and unawareness/misconceptions/myths about vascular diseases, were the major challenges being faced by the vascular community for their separate identity.

Conclusion: The vascular community is facing great challenges of shortage of qualified vascular surgeons and technicians, inadequate training centers, part time vascular surgery and misconceptions/myths/unawareness about vascular diseases.

Keywords: Acceptability, Medical community, Separate specialty, Vascular surgeon.

How to Cite This Article: Jamil M, Jamil B, Aman A, Usman R. Challenges Faced by Vascular Surgeons in Acceptance of Their Specialty by Medical Community of Pakistan. Pak Armed Forces Med J 2021; 71(5): 1857-1860. $\quad$ doi: https://doi.org/10.51253/pafmj.v71i5.4153

This is an Open Access article distributed under the terms of the Creative Commons Attribution License (https://creativecommons.org/licenses/by-nc/4.0/), which permits unrestricted use, distribution, and reproduction in any medium, provided the original work is properly cited.

\section{INTRODUCTION}

Medicine has seen a proliferation of specialties including vascular surgery over the last 50 years, as scientific discovery and care delivery advanced. Vascular surgery is a subspecialty in which diseases of vascular system or arteries, veins and lymphatic circulation are managed by medical therapy, minimal invasive catheter procedures (endovascular) and surgical reconstruction..$^{1-3}$ The specialty evolved from general surgery, cardiac surgery and minimal invasive techniques pioneered by interventional radiology. 4 The vascular surgeon is trained in diagnosis and management of diseases affecting all parts of vascular system excluding coronaries and intracranial vasculature.5,6

Vascular surgery has been recognized as separate specialty in most of the world, but this process is very slow in Pakistan and still it is being governed by part time vascular surgeons. ${ }^{7}$ As they are not trained for vascular diseases, it is resulting in suboptimal treatment and lack of ownership of the patients. The vascular community is continuously facing a lot of challenges to

Correspondence: Dr Muhmmad Jamil, HOD Vascular Surgery, Combined Military Hospital, Rawalpindi Pakistan

Received: 24 Apr 2020; revision received: 10 May 2020; accepted: 13 May 2020 overcome this identity crises and recognition of vascular surgery as a separate specialty $.8,9$

This study was conducted to find all those challenges being faced by vascular community to get through this difficult situation. It may help in recognition and acceptability of specialty. Our suggestions will help in provision of international standard vascular care by qualified vascular surgeon and decrease the mortality and morbidity of these patients.

\section{METHODOLOGY}

This qualitative case study was conducted at Combined Military Hospital Rawalpindi, from September 2019 to February 2020 by interviewing vascular (7) and part time vascular (06) surgeons .

Inclusion Criteria: Surgeons practicing vascular surgery from different cities of Pakistan were included.

Exclusion Criteria: Non-consenting vascular surgeons were excluded.

Interviews were audio recorded in persons for Rawalpindi and telephonic for Islamabad, Lahore, Multan, Karachi and Quetta.

All vascular surgeons and part time vascular surgeons (general surgeons, cardiac surgeons and 
interventional radiologist) working in various teaching hospitals/institutions of Pakistan, for the last five years, were included in the study.

Vascular surgeons/part time vascular surgeons having less experience than 5 years in specialty, not working in teaching institution/hospital, were excluded from the study.

Written informed consent was obtained on a form, providing detailed information about the study and liberty to withdraw at any time, from all the participants. Data was collected from 13 vascular surgeons/ part time vascular surgeons from all provinces of Pakistan through semi structured interviews based on series of open ended and broad questions which were asked. It allowed us to prompt/encourage the interviewee for more information and freedom to be probed in order to acquire an elaborated and detailed inquiry. The interview conversations were audio recorded through telephone calls and direct recording of in personal interviews (Nine surgeons interviewed in persons while 4 were interviewed on telephone). There was no video recording of interview as data was analyzed by narrative explanation thematic analysis only. There was no restriction of language to remove the language barrier. Probes and prompts as included in interview format were used to extract maximum desirable information. The interviews were transcribed into English text through transcribers.

Data cleansing was done by author to shrink the data and make it easy to understand the concept of discussion in interview.

Inductive data analysis and thematic content analysis was performed in our study under following steps: i) Important facts surrounding the case were identified first by taking notes, high lighting relevant facts and underlying key problems. ii) the key issue was identified ( $2-5$ bullet points) as first inductive coding. iii) second inductive coding was done by an expert for validation of qualitative research. iv) the course of action was specified and evaluated. v) the best course of action was recommended.

The process of data collection, transcription and analysis was validated by ensuring credibility, transferability, dependability and conformability.

\section{RESULTS}

Handful of qualified vascular surgeons, inadequate vascular training program, part time vascular surgery and unawareness/misconceptions/myths about vascular diseases, were the major challenges being faced by the vascular community for their separate identity.

The following issues which vascular community was facing to establish a separate identity, were identified as shown in the Table.

\section{Table: Issues Identified.}

Inadequate qualified vascular surgeons
Part time vascular surgery
Inadequate vascular training program
Unawareness of general public and medical community
about nature, severity, diagnosis and treatment of vascular
diseases.
Lack of infrastructure for vascular surgery
Misconceptions and myths about vascular diseases
Lack of patient ownership
Suboptimal treatment of patients with vascular diseases
Late recognition of vascular surgery by College of
Physicians and Surgeons of Pakistan
Lack of trained manpower
Late presentation of patients to doctors
Late referral to vascular surgeon
Long distance and transportation problems

The common misconception and myths determined in our study were, i) 'vascular diseases are diseases of the white people', ii) 'reconstructive bypass procedures cannot save limb and life', iii) 'vascular surgery is part of general surgery' iv) cardiothoracic surgeons believe, 'it belongs to them'.

\section{DISCUSSION}

Vascular surgery evolved from general surgery, isolated from cardiovascular surgery and started to develop into separate specialty almost 30 years back in developed countries. ${ }^{7}$ In Pakistan, the vascular surgery is still in infancy stage due to lot of active issues resulting in slow development of the specialty. Therefore, we can say, identity crises are there. ${ }^{8}$ We conducted this qualitative study to explore all those problems posing big challenges to the vascular surgeons to overcome this identity crises. Soon, we will have full fledge vascular departments headed by qualified and trained vascular surgeons in major healthcare facilities in general and teaching hospitals. ${ }^{8}$ The vascular diseases are killing and crippling as many people as by the cardiac diseases and cancer in Pakistan and the disease load is directly increasing with increasing risk factors (diabetes mellitus, hypertension, obesity, smoking, sedentary lifestyle, junk food and stress, motor vehicle accident, assault and crime). ${ }^{11,12}$ Treatment of these sort of patients by skillful vascular surgeons can only improve their quality of life. 
To deal with this much load of vascular diseases, there are only a handful of qualified vascular surgeons in Pakistan. The study suggested that inadequacy of qualified vascular surgeons in Pakistan, is probably the largest issue. In 2005, there were only 7 dedicated vascular surgeons in Pakistan whereas in USA, there were 2900. At present, we have only 12 qualified vascular surgeons covering all the private and Govt sectors. Although the developed countries have well established vascular departments but still, they are in short of vascular surgeons at present according to their needs. ${ }^{13}$ Harkin et al, has explained this shortage of vascular surgeons by preference of controlled lifestyle by doctors. ${ }^{13}$ Aggressive steps must be required to overcome this shortage of vascular surgeons. The following suggestions may help to increase the qualified vascular surgeons, i) increase supervisors in vascular surgery, ii) increase recognized training centers, iii) training slots should be increased in recognized centers.

Part time vascular surgery is second major issue determined in our study, effecting growth of the specialty ${ }^{14}$. The training of cardiac surgery, general surgery and orthopedic surgery is quite different from vascular training. The approach, diagnosis and management of vascular diseases are very different from all these specialties doing vascular surgery as part time activity. ${ }^{8}$ Cardiac surgeons are technically competent enough to do the vascular anastomosis, but they are already overburdened due to cardiac bypass and valve replacement. Same is true for general and orthopedic surgeons. Recently cardiologist and radiologist started to treat vascular diseases. This practice is in not only Pakistan but also more in other developing countries. This part time activity results in lack of patient ownership, lack of communication, part time patient care and lack of holistic approach and hence intervention may be harmful to the patient instead of benefitting him. ${ }^{15}$ To meet with this challenge; the general surgeons must go through a structured vascular training program for 6 months and allowed to treat only vascular trauma and emergency. Cardiologist, radiologist and orthopedic surgeons should be restricted to their specialty. Cardiac surgeons if trained in old cardiovascular centers, should be allowed to treat common vascular disease

Inadequate structured training program for vascular surgery is the next major challenge for vascular surgeons. ${ }^{16}$ Presently only 6 recognized training institution/teaching hospital, are there in Pakistan. Four of these are recently recognized by CPSP and can train only one candidate. There is only one training program for this specialty in Pakistan. College of Physicians and Surgeons of Pakistan started few years back, a training program as two years exclusive fellowship in vascular surgery. The other training program is clinical fellowship in vascular surgery was being run by Agha khan university, has been merged probably with FCPS in vascular surgery. The same issues exist in India where again two training programs (Chennai and Dehli) are running. ${ }^{7}$ To meet with this challenge; recognized independent vascular units are established in all teaching hospitals/training institutions. Certification based on six months training in vascular surgery, should be started for general surgeons working in periphery to treat vascular trauma and emergencies. Certification in vascular surgery for urologists should be started for anastomosis and venous access.

Unawareness about the nature and severity of vascular diseases by general public and medical community is a big dilemma of this specialty. Pain in legs and toes is taken for many years as arthritis and sciatica till the time gangrene occurs and amputation is done leaving primary problem behind. ${ }^{17}$ Neither patients, nor the doctors know who will own these patients. The lack of awareness of vascular disease and specialty is so grave that even some cardiothoracic surgeons have never heard of a separate, independent vascular surgery department or a vascular surgeon which is actually truly tragic situation. To encounter this challenge, hands on vascular workshops on regular basis for medical and paramedical staff need to be conducted. Health education related to vascular diseases should be imp-roved through social and electronic media. Written material related to vascular diseases should be available at all health provider clinics.

Misconception and myth about the specialty is another great challenge for the vascular community ${ }^{18}$. Vascular problems timely intervened by expert hands, have saved many limbs and lives. Overburdened general and cardiothoracic surgeons have different training program mainly focused around their specialties perform vascular surgery as part time activity not more than $2 \%$ of the total vascular load. The senior surgeons worked in that era of time when all-rounder in medicine were encouraged but now masters are need of specialty not the all rounders. The steps that can encounter these misconceptions and myths, i) national registry for high-risk patient should be encouraged, ii) data of patients treated by skilled vascular surgeons should be published at national level. 
Endovascular surgery needs highly specified infrastructure to be practiced. In Pakistan and third world countries, very less independent department of endovascular surgery, are present. ${ }^{19}$ Allocation of extra budget, may improve the situation.

Availability of the record of the vascular patients at national level, can play an important role in understanding the significance of the specialty. The data of patients attended at private clinics and by part time vascular surgeons, is not usually maintained in developing countries. Exact information about burden of diseases, is very important to calculate human resource. ${ }^{20}$ Screening for vascular diseases in high-risk patients and central registry of patients can play a pivotal role in specialty acceptance.

Deficiency of trained vascular nurses and paramedics is predicted in our study. The trained staff is backbone of the specialty. Studies had suggested that USA and UK are also facing shortage of work-force ${ }^{21,22}$. Eastern countries are facing almost similar problems of deficiencies of vascular surgeons and vascular technicians.

\section{CONCLUSION}

Shortage of qualified vascular surgeons and staff, lack of vascular training centers, lack of highly specific infrastructure, misconception and myths about vascular diseases and part time vascular surgery, are the major issues (determined in our study) being faced by vascular surgeons for acceptability of their specialty.

Therefore, this is high time that development of vascular surgery as a separate discipline is given a serious thought by all those concerned. By doing this, we would be able to provide international standards vascular services and reduce the morbidity and mortality.

\section{Conflict of Interest: None.}

\section{Authors' Contribution}

MJ: Data collection, writing, data analysis, revision, BJ: Supervision of data, proof reading, AA: Interpretation of data, RU: Data revision.

\section{REFERENCES}

1. Marsman MS, Wetterslev J, Vriens PWHE, Bleys RLAW, Jahrome $\mathrm{AK}, \mathrm{Moll} \mathrm{FL}$, et al. Eversion technique versus conventional endarterectomy with patch angioplasty in carotid surgery: protocol for a systematic review with meta-analyses and trial sequential analysis of randomised clinical trials. BMJ Open 2020; 10(4): e030503.

2. Abbott AL, Brunser AM, Giannoukas A, Harbaugh RE, Kleinig $\mathrm{T}$, Lattanzi S, et al. Misconceptions regarding the adequacy of best medical intervention alone for asymptomatic carotid stenosis. J Vasc Surg 2020; 71(1): 257-269.
3. Schneider PA1, Varcoe RL. Risk of death and amputation with use of paclitaxel-coated balloons in the infrapopliteal arteries for treatment of critical limb ischemia: a systematic review and meta-analysis of randomized controlled trials. J Vasc Interv Radiol 2020; 31(2): 202-212.

4. Cronenwett JL, Johnston KW. Rutherford's Vascular Surgery EBook. Elsevier Health Sciences; 2014, [Internet] Available from: https://books.google.com.pk/books/about/Rutherford_s_Vascular_Surgery_E_Book.html?id=YcY0AwAAQBAJ\&redir_esc=y

5. Duncan AA, Power AH. Vascular surgery resident training in Canada. Semin Vasc Surg 2019; 32(1-2): 18-20.

6. Shames M, Bandyk D. Introduction: Evolution of vascular surgery training-Apprentice to fellow to integrated resident. Semin Vasc Surg 2019; 32(1-2): 1-4.

7. Rehman ZU, Sophie Z. Vascular surgery in Pakistan: critical issues. J Coll Physician Surg Pak 2014; 24(6): 381-382.

8. Singh D, Jawaid SA. Identity crisis: who is a vascular surgeon?. Pak J Med Sci 2006; 22(1): 3-5.

9. Nochomovitz $M$, Sharma R. Is it time for a new medical specialty? The medical virtualist. JAMA 2018; 319(5): 437-438.

10. Irfan W, Sheahan C, Mitchell EL, Sheahan MG. The pathway to a national vascular skills examination and the role of simulationbased training in an increasingly complex specialty. Semin Vasc Surg 2019; 32(1-2): 48-67.

11. Aziz KU, Faruqui A. Prevalence and awareness of cardiovascular disease including life style in a lower middle class urban community in an Asian country. Pak Heart J 2012; 41(1): 3-4.

12. Shabbir S, Jamal S. Outcome of vascular trauma at Pakistan Institute of Medical Sciences, Islamabad. Ann Pak Inst Med Sci 2011; 7(1): 29-32.

13. Harkin DW, Beard JD, Shearman CP, Wyatt MG. Predicted shortage of vascular surgeons in the United Kingdom: a matter for debate. Surg 2016; 14(5): 245-251.

14. Cronenwett JL, Kraiss LW, Cambria RP. The society for vascular surgery vascular quality initiative. J Vasc Surg 2012; 55(5): 15291537.

15. Goodney PP, Fisher ES, Cambria RP. Roles for specialty societies and vascular surgeons in accountable care organizations. J Vasc Surg 2012; 55(3): 875-882.

16. Williams Jr TE, Satiani B, Thomas A, Ellison EC. The impending shortage and the estimated cost of training the future surgical workforce. Ann Surg 2009; 250(4): 590-597.

17. Zil-E-Ali A, Rashid A. Vascular Surgery. Profes Med J 2017; 24(05): 639-640.

18. Ziegler MA, DiStasi MR, Bills RG. Marvels, mysteries, and misconceptions of vascular compensation to peripheral artery occlusion. Microcircul 2010; 17(1): 3-20.

19. Sedrakyan A, Cronenwett JL, Venermo M, Kraiss L, MarinacDabic D, Björck M. An international vascular registry infrastructure for medical device evaluation and surveillance. J Vasc Surg 2017; 65(4): 1220-1222.

20. Kentley J, Fox A, Taylor S, Filipek A. The use of a pro forma to improve quality in clerking vascular surgery patients. BMJ Open Qual 2016; 5(1): u210642-w4280.

21. Kane K, Rosero EB, Clagett GP, Adams-Huet B, Timaran CH. Trends in workforce diversity in vascular surgery programs in the United States. J Vasc Surg 2009; 49(6): 1514-1519.

22. Go MR, Oslock WM, Way DP, Baselice HE, Tamer RM, Kent KC, et al. An updated physician workforce model predicts a shortage of vascular surgeons for the next 20 years. Ann Vasc Surg 2020; 66(2): 282-288. 